\title{
Sol-Gel-Derived Porous Silica: Economic Synthesis and Characterization
}

\author{
Enobong R. Essien ${ }^{1}$, Oluyemi A. Olaniyi ${ }^{1}$, Luqman A. Adams ${ }^{2}$, Rafiu O. Shaibu ${ }^{2}$ \\ ${ }^{1}$ Department of Chemical Sciences, College of Natural Sciences, Bells University of Technology, Ota, Nigeria \\ ${ }^{2}$ Department of Chemistry, Faculty of Science, University of Lagos, Lagos, Nigeria \\ Email: beautyingardens@yahoo.com
}

Received August 8, 2012; revised September 12, 2012; accepted September 20, 2012

\begin{abstract}
Porous silica was synthesized via the sol-gel process using clay obtained locally from Ijero-Ekiti in Ekiti State, Nigeria and compared with silica synthesized under similar conditions from sodium metasilicate $\left(\mathrm{Na}_{2} \mathrm{SiO}_{3}\right)$ obtained comercially. The clay was initially refluxed with sodium hydroxide $(\mathrm{NaOH})$ for 2 hours to extract $\mathrm{SiO}_{2}$ to form $\mathrm{Na}_{2} \mathrm{SiO}_{3}$, which was subsequently hydrolyzed to form a gel. The gel obtained was washed with deionized water to get rid of impurities, dried and calcined at $800^{\circ} \mathrm{C}$ for 3 hours. The obtained silica powders were characterized using atomic absorption spectrophotometer, Fourier transform infrared (FTIR) spectroscopy, X-ray diffraction (XRD) and scanning electron microscopy (SEM). Results showed that the vibrational modes and diffraction patterns of the silica derived from commercial $\mathrm{Na}_{2} \mathrm{SiO}_{3}$ and that prepared from clay were similar containing pure amorphous $\mathrm{SiO}_{2}$. The morphology of the commercially obtained silica showed better arrangement of particles and exhibited slightly lesser porosity (62.4\%) compared to that derived from clay which had a porosity of $65.5 \%$. The result indicates that clay has a potential for use as an environmentally safe and economic starting material for preparing porous silica instead of high quality precursors.
\end{abstract}

Keywords: Clay; Sodium Metasilicate; Economic; Porous Silica; Environmentally Safe

\section{Introduction}

Porous silica is used in many fields including biotechnology, biomedical sciences, selective separation and catalysis $[1,2]$. Unlike conventional glass, which is a viscous fluid that results from the fusion of $\mathrm{SiO}_{2}$ at high temperature, sol-gel-derived silica is obtained at mild conditions [3] compatible with the stability of most bioactive compounds. The sol-gel process is capable of generating materials with controlled surface properties and pore structures between $1-500 \mathrm{~nm}$ [4-7]. The matrix of the silica thus formed can be exploited for immobilization of biomolecules or cations, inorganic membranes and support for catalysts [6-9].

Silica polymer networks may be obtained by hydrolysis and condensation reactions of silica precursors such as tetraethyl orthosilicate (TEOS). By controlling synthesis conditions carefully, the sol morphology can be directed towards weakly branched polymeric systems or to particulate systems [7]. Important process parameters include water content, the solvent, the catalyst used and its concentration and type of alkoxide used $[4,10,11]$.

Several methods, most of them based on TEOS as starting material have been used to prepare porous silica. The most popular is the sol-gel synthesis proposed by

\footnotetext{
"Corresponding author.
}

Stöber et al. [12] which is based on hydrolysis and condensation of highly reactive silicon alkoxide precursor at low temperature. Consequently, silica particles with various characteristics were prepared by ammonia-catalyzed reactions of tetraethyl orthosilicate (TEOS) with water in low molecular weight alcohol $[12,13]$. Due to high cost, applicability of other precursors has been investigated. Thus, different types of silica sources have been used, such as sodium silicate $[14,15]$ and even environmentally safe and renewable resources, like rice husk ash [16,17], rice hull ash [18] and rice straw ash [19] have also been exploited.

In continuation of the search for a cheap and environmentally safe silica source, the work herein investigated the synthesis of porous silica from clay and sodium metasilicate under similar conditions for the purpose of comparing their physical and morphological characteristics.

\section{Materials and Methods}

\subsection{Materials}

The chemicals used were sodium metasilicate $\left(\mathrm{Na}_{2} \mathrm{SiO}_{3}\right)$, (Sigma-Aldrich) with composition $\mathrm{SiO}_{2} 24.9$ and $\mathrm{Na}_{2} \mathrm{O}$ $20.9 \mathrm{wt} \%$ respectively, clay from Ijero-Ekiti in Nigeria 
having composition (as previously analyzed by Olasupo and Omotoyinbo [20]) as shown in Table 1 and sulphuric acid $\left(\mathrm{H}_{2} \mathrm{SO}_{4}\right)$, (Fluka, Germany).

\subsection{Preparation of Porous Silica from Sodium Metasilicate (SS)}

Sodium metasilicate $(5.0 \mathrm{~g})$ was stirred in distilled water $(10.0 \mathrm{ml})$ to give a clear solution. Thereafter, $10.0 \mathrm{ml}$ of $2 \mathrm{M} \mathrm{H}_{2} \mathrm{SO}_{4}$ was added dropwise to the mixture under magnetic stirring at room temperature for about 2 hours to form a gel. Deionized water was added successively to the gel to wash and remove sodium sulphate $\left(\mathrm{Na}_{2} \mathrm{SO}_{4}\right)$. Complete removal of sodium ions was indicated by absence of white precipitate when the liquid from the last filtration was tested with dilute lead(II) ethanoate solution. The washed gel was dried in an oven at $120^{\circ} \mathrm{C}$ for 1 day, calcined at $800^{\circ} \mathrm{C}$ for 3 hours in a furnace with a heating rate of $10^{\circ} \mathrm{C} / \mathrm{min}$ and thereafter milled to form powders and then labelled as SS.

\subsection{Preparation of Porous Silica from Clay (CS)}

The as-received potter's clay was dried in the sun, following which it was ground into powder in a ball mill and sieved through a $100 \mu \mathrm{m}$ to remove oversize particles. The obtained clay $(10.0 \mathrm{~g})$ was refluxed in $1 \mathrm{M}$ $\mathrm{NaOH}$ solution $(200.0 \mathrm{ml})$ for 2 hours, then allowed to cool before filtering to remove the residue which contained $\mathrm{Al}(\mathrm{OH})_{3}$ as major impurity. The filtrate obtained was evaporated to dryness to give as residue sodium metasilicate, $\mathrm{Na}_{2} \mathrm{SiO}_{3}(5.0 \mathrm{~g})$. The basic sodium metasilicate was dissolved in distilled water $(10.0 \mathrm{ml})$. The solution was hydrolyzed with $2 \mathrm{M} \mathrm{H}_{2} \mathrm{SO}_{4}(20.0 \mathrm{ml})$ and subsequently treated the same way as in section 2.2 above to afford the silica powder which will henceforth be called CS.

\section{Characterization}

X-ray diffraction (XRD) analysis was carried out in the $2 \theta$ range of $10^{\circ}-80^{\circ}$ and $5^{\circ}-120^{\circ}$ using Xpert PRO PANalytical diffractometer employing $\mathrm{CuK} \alpha$ radiation

Table 1. Mineralogical composition of Ijero-Ekiti clay.

\begin{tabular}{cccc}
\hline Minerals & Amount (\%) & Oxides & Composition (\%) \\
\hline Kaolinite & 72 & $\mathrm{SiO}_{2}$ & 63.3 \\
Quartz & 22 & $\mathrm{Al}_{2} \mathrm{O}_{3}$ & 16.5 \\
Feldspar & 4 & $\mathrm{Fe}_{2} \mathrm{O}_{3}$ & 5.8 \\
Illite & 2 & $\mathrm{CaO}$ & 1.7 \\
& & $\mathrm{MgO}$ & 0.6 \\
& & LoI & 12.5 \\
& & Others & 0.8 \\
\hline
\end{tabular}

LoI $=$ Loss on ignition
$(0.154060 \mathrm{~nm})$ source operated at $40 \mathrm{kV}$ and $40 \mathrm{~mA}$. Fourier transform infrared spectroscopy (FTIR) studies were carried out using Buck Scientific 500 Infrared spectrophotometer with $\mathrm{KBr}$ as reference in the wave number range of $600-4000 \mathrm{~cm}^{-1}$. Atomic absorption spectroscopy Perkin Elmer A Analyst 200 was used to determine residual amount of sodium ions $\left(\mathrm{Na}^{+}\right)$present in the silica networks. Morphological characterization of the samples regarding the particles and pore sizes distribution were performed using a SEM (EVO/MA10) at an accelerating voltage of $10 \mathrm{kV}$.

The bulk densities, $\rho_{b}$ of the silica particles were measured from their weight to volume ratio using the formula

$$
\rho_{b}=M / V
$$

where, $M$ is the mass of the sample measured with a microbalance $\left(10^{-5} \mathrm{~g}\right.$ accuracy), and $V$ is the volume measured by filling the silica particles in a column of known volume [21].

The porosity, $P(\%)$ was estimated using the relationship [22]

$$
P=\left(1-\rho_{b} / \rho_{p}\right) \times 100
$$

in which $\rho_{\mathrm{p}}$ is specific density assumed to be $2.0 \mathrm{~g} \cdot \mathrm{cm}^{-3}$ for amorphous silica particles based on the sperical model (a typical average density of silica prepared via wet-synthesis conditions [23]).

\section{Results and Discussion}

\subsection{Hydrolysis and Gelation}

Acidic hydrolysis of sodium metasilicate $\left(\mathrm{Na}_{2} \mathrm{SiO}_{3}\right)$ gives silicic acid [24] in solution. Sodium hydroxide is reacted with clay to initially afford sodium metasilicate in a strongly basic medium. The water glass obtained from the basic reaction is similarly hydrolysed to silicic acid which undergoes condensation to disilicic acid and further reaction to a polycondensed hydrogel [24] as shown in Scheme 1. Thereafter, the gel obtained from both precursor compounds were subjected to multiple washings [25] with deionised water to free the gel of sodium sulphate formed during hydrolysis that is trapped in the pores of the gel network. During aging, the 3-D framework of the silicate glass continues to grow and becomes more rigid by contracting and expelling liquid water present inside the pores [26]. Drying is important as it modifies the gel characteristics and involves two steps [27]. During the first step, the pores are emptied; the capillary gradient induces the liquid flow along the pore walls, towards the external surface where it evaporates. At the interior, the pores are still filled with liquid, while the air enters the most external pores, which can cause the opacity of gel. The pressure capillary gradient decreases gradually, the flow is increasingly slower then 


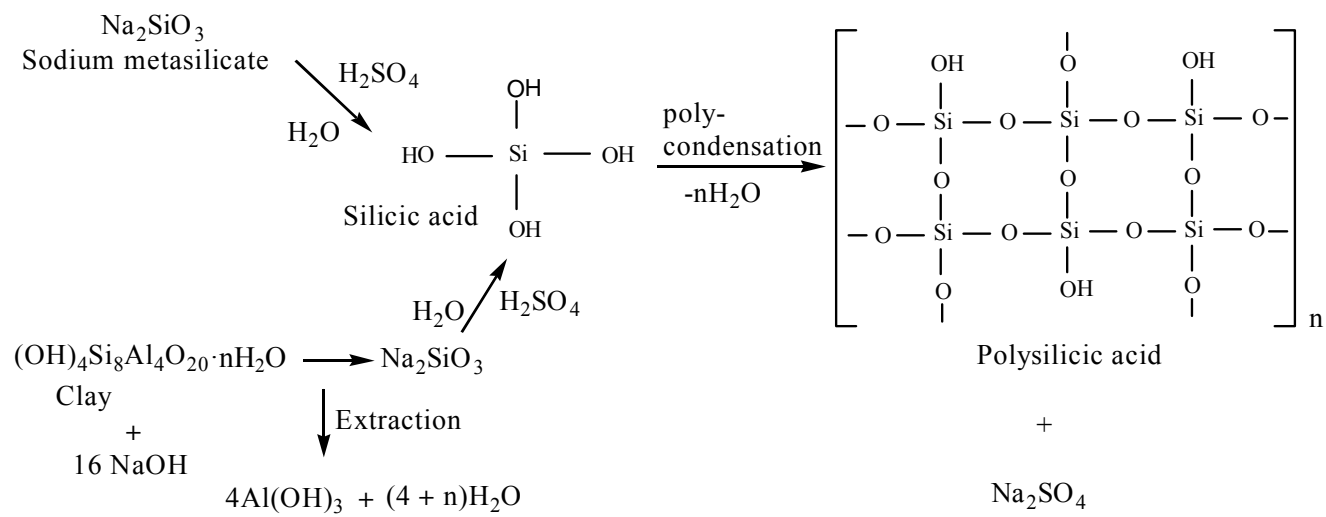

Scheme 1. Hydrolysis and polycondensation of sodium metasilicate and clay.

stops. In the second step the remaining liquid can then leave the gel only in gas form, with vapour diffusion towards the surface. After drying at $120^{\circ} \mathrm{C}$, the porous gel contains a small quantity of liquid trapped in the pores. Calcination at high temperature further removes absorbed water trapped in the pores.

The efficiency of deionised water washings to free the gel from sodium sulphate was monitored by atomic absorption spectroscopy (AAS) analysis of the silicas obtained after drying. The result indicated that $\mathrm{Na}^{+}$ decreased from $36.5 \%$ (on the basis of stoichiometry) [25] to $1.6 \%$ in the SS-based silica and to $2.1 \%$ in the $\mathrm{CS}$ based silica.

\subsection{Bulk Density and Porosity}

The silica obtained from SS and CS after calcination were found to have bulk density of 0.752 and $0.690 \mathrm{~g}$ $\mathrm{cm}^{-3}$ respectively. The difference may be due to better packing of the 3-D framework in the SS as a result of more efficient removal of the interfering $\mathrm{Na}^{+}$from successive deionized water washings of the gels [28]. Their bulk densities as expected had influence on their porosity, as SS and CS exhibited $62.4 \%$ and $65.5 \%$ respectively.

\subsection{FTIR}

The FTIR spectra obtained for the SS and CS-based silicas respectively are characterized by a broad band centred around $3400 \mathrm{~cm}^{-1}$ and a smaller signal around $1630 \mathrm{~cm}^{-1}$ that corresponds to $\mathrm{O}-\mathrm{H}$ absorption band [29,30] as shown in Figures 1(a) and (b). Furthermore, a diagnostic $\mathrm{Si}-\mathrm{O}-\mathrm{Si}$ asymmetric stretching vibration is centred on $1132 \mathrm{~cm}^{-1}$ [31,32] and the absorption signal at $920 \mathrm{~cm}^{-1}$ is assigned to the stretching vibration of silanol groups on the surface of the amorphous solid [33].

\subsection{XRD}

The XRD spectra of the SS and CS powders obtained are shown in Figures 2(a) and (b) respectively. The diff- raction patterns are similar for both samples which appear as broad bands with reflection at $2 \theta=22^{\circ}$ indicating that the materials are amorphous and composed of $\mathrm{SiO}_{2}$ [34-36]. There are no additional peaks observed in both spectra. This result indicates the absence of impurities in the gel networks after the deionised water washing removal of $\mathrm{Na}_{2} \mathrm{SO}_{4}$ formed during the gelation reaction (Scheme 1), the extent which was confirmed earlier with AAS.

\subsection{SEM}

The particle sizes of the silicas measured by SEM are presented in the micrographs shown in Figure 3. The average particle size of SS was $353.95 \mathrm{~nm}$, Figure 3(a) while that of CS was $755.35 \mathrm{~nm}$, Figure 3(b). The difference in particle sizes in the two samples may be the result of agglomeration [37] which is higher in CS than $\mathrm{SS}$. This fact is more evident in Figure $\mathbf{4}$ where in the micrograph of SS, Figure 4(a), the particles appear as discrete with a few agglomerates, whereas the particles of CS as seen in the micrograph shown in Figure 4(b), appear to adhere to each other forming aggregate of particles which results in irregular arrangement when compared to SS. It has been proposed [38] that the initial particle size distribution, polydispersity, concentration of particle size distribution, polydispersity, concentration of particles, viscosity of the continuous phase, Van der Waals forces of attraction, and hydrodynamic conditions govern the extent of inter-particle collisions, aggregation and the temporal evolution of the average diameter of aggregates. The morphology of CS therefore appears to be more porous than that of SS which agrees with the porosity values earlier obtained. According to studies [39], porosity arises from the assumed packing of primary particles in the agglomerates.

\section{Conclusion}

Porous silica has been successfully synthesized via an 

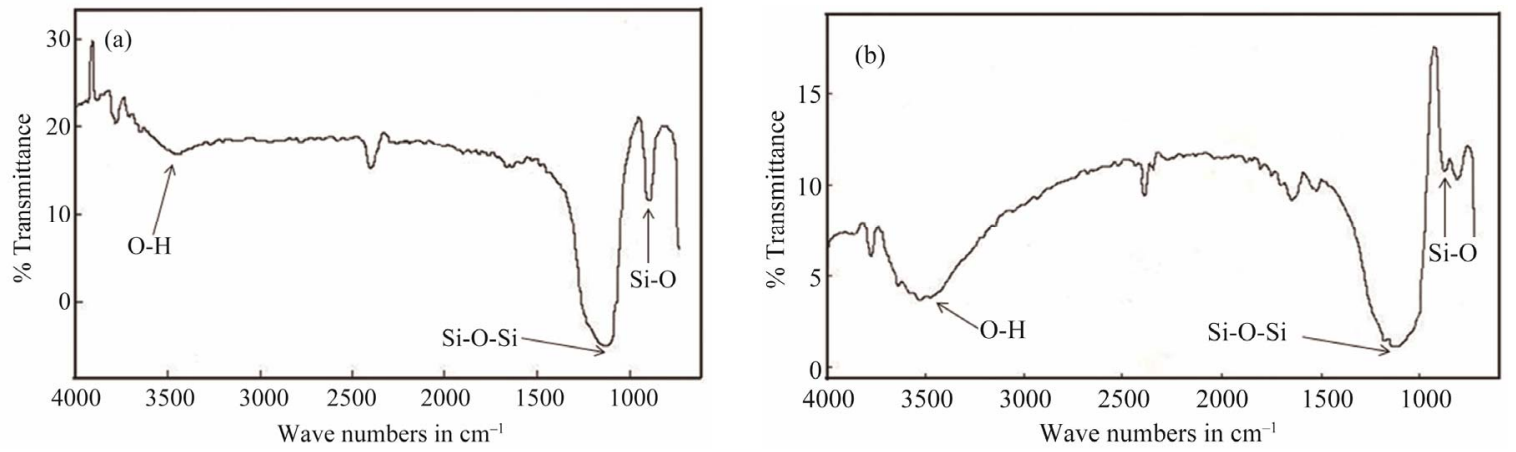

Figure 1. (a) FTIR spectrum of SS-based silica; (b) FTIR spectrum of CS-based silica.
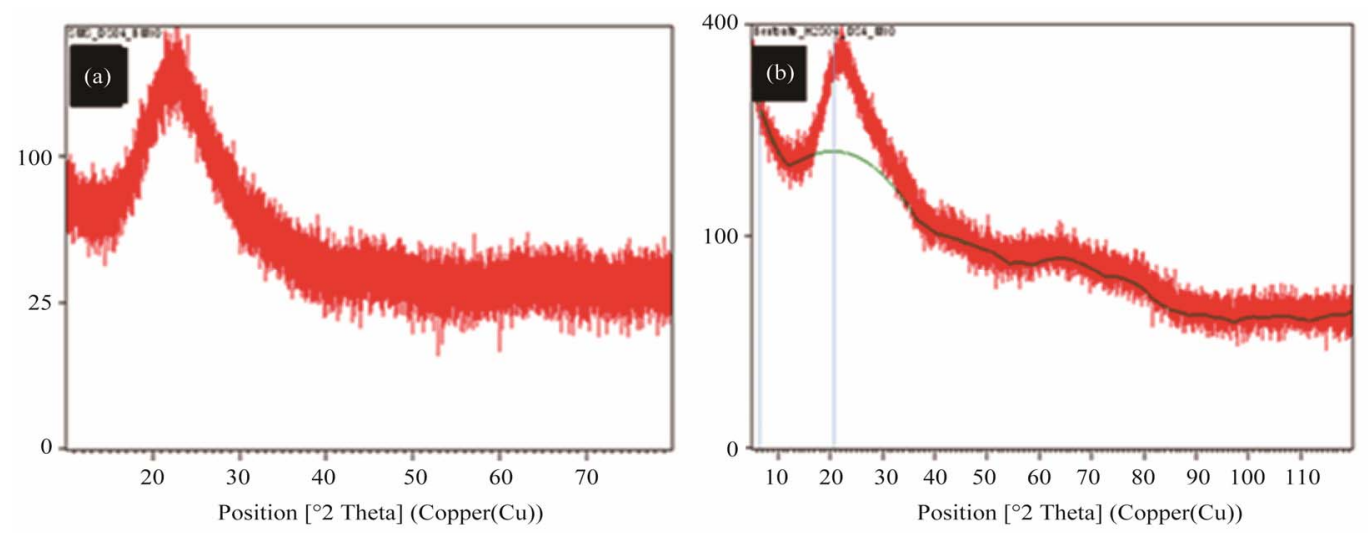

Figure 2. XRD patterns obtained from (a) SS and (b) CS powders.
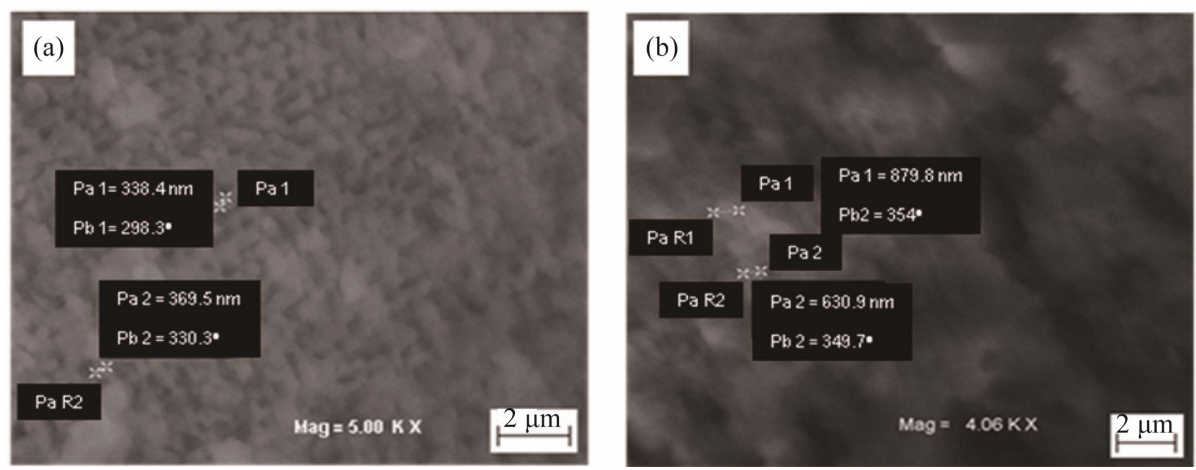

Figure 3. SEM micrographs of samples (a) SS and (b) CS showing particle sizes measured at different positions: Pa 1 and Pa 2 at positional angles of $\mathrm{Pb} 1$ and $\mathrm{Pb} 2$ respectively.
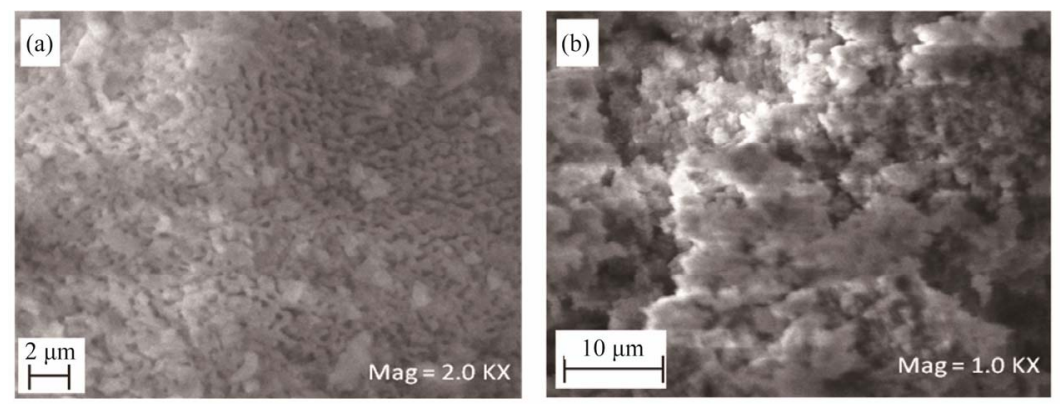

Figure 4. SEM micrographs showing the porous morphology of the sol-gel-derived silicas. It can also be seen that SS, (a) contains better packed particles than CS, (b). 
economic route using a Nigerian clay. Results obtained from FTIR, XRD and SEM characterization showed that the material possessed properties comparable to silica obtained from commercial sodium metasilicate prepared under the same conditions. It is therefore concluded that clay which is cheap and widely available in Ekiti State, Nigeria may be a potential starting material for commercial scale preparation of porous silica.

\section{Acknowledgements}

The authors are grateful to the Central Research Laboratory, Bells University of Technology, Ota, Nigeria for their assistance in carrying out this project.

\section{REFERENCES}

[1] F. He, R. X, Zhuo, L. J. Liu, D. B. Jin, J. Feng and X. L Wang, "Immobilized Lipase on Porous Silica Beads: Preparation and Application for Enzymatic Ring-Opening Polymerization of Cyclic Phosphate," Reactive Functional Polymers, Vol. 47, No. 2, 2001, pp. 153-158. doi:10.1016/S1381-5148(01)00027-X

[2] K. W. Gallis, J. T. Araujo, K. J. Duff, J. G. Moore and C. C. Landry, "The Use of Mesoporous Silica in Liquid Chromatography," Advanced Materials, Vol. 11, No. 17, 1999, pp. 1452-1455.

doi:10.1002/(SICI)1521-4095(199912)11:17<1452::AIDADMA1452>3.0.CO;2-R

[3] H. Bottcher, P. Slowik and W. Suss, "Sol-Gel Carrier Systems for Controlled Drug Delivery," Journal of SolGel Science and Technology, Vol. 13, No. 1-3, 1998, pp. 277-281. doi:10.1023/A:1008603622543

[4] K. Agrawal, G. Singh, D. Puri and S. Prakash, "Synthesis and Characterization of Hydroxyapatite Powder by SolGel Method for Biomedical Application," Journal of Minerals \& Materials Characterization \& Engineering, Vol. 10, No. 8, 2011, pp. 727-734.

[5] U. Damrau and V. Marsmann, "Hydrolysis of Oligomer Intermediates in the Sol-Gel Process," Journal of NonCrystalline Solids, Vol. 168, No. 1-2, 1994, pp. 42-48. doi:10.1016/0022-3093(94)90118-X

[6] R. F. S. Lenza and W. L. Vasconcelos, "Synthesis and Properties of Microporous Sol-Gel Silica Membranes," Journal of Non-Crystalline Solids, Vol. 273, No. 1-3, 2000, pp. 164-169. doi:10.1016/S0022-3093(00)00163-0

[7] H. S. Mansur, R. L. Oréfice, W. L. Vasconcelos, R. F. S. Lenza and Z. Lobato, "Sol-Gel Silica Based Networks with Controlled Chemical Properties," Journal of NonCrystalline Solids, Vol. 273, No. 1-3, 2000, pp. 109-115. doi:10.1016/S0022-3093(00)00150-2

[8] N. K. Raman, T. L. Ward, C. J. Brinker, R. Sehgal, D. M. Smith, Z. Duan, M. Hampden-Smith, J. K. Bailey and T. J. Headly, "Catalyst Dispersion on Supported Ultramicroporous Inorganic Membranes Using Derivatized Silylation Agents," Applied Catalysis A: General, Vol. 96, No. 1, 1993, pp. 65-82. doi:10.1016/0926-860X(93)80007-D

[9] J. K. Kumar, R. Ramesh, G. Kanchana, P. Suresh and P.
Sundaramoorthi, "Nucleation Reduction Strategy of $\mathrm{SrNH}_{4} \mathrm{MgPO}_{4}$ (Strontium Ammonium Magnesim Hydrogen Phosphate) Crystal Growth in Silica Gel Medium and its Characterization Studies," Journal of Minerals \& Materials Characterization \& Engineering, Vol. 8, No. 6, 2009, pp. 439-453.

[10] R. S. A. de Lange, J. H. A. Hekkink, K. Keizer and A. J. Burggraaf, "Polymeric-Silica-Based Sols for Membrane Modification Application: Synthesis and Characterization with SAXS," Journal of Non-Crystalline Solids, Vol. 191, No. 1-2, 1995, pp. 1-16. doi:10.1016/0022-3093(95)00291-X

[11] R. F. S. Lenza and W. L. Vasconcelos, "Structural Evolution of Silica Modified with Formamide," Materials Research, Vol. 4, No. 3, 2001, pp. 175-179. doi:10.1590/S1516-14392001000300006

[12] W. Stöber, A. Fink and E. Bohn, "Controlled Growth of Monodisperse Silica in the Micron Size Range," Journal of Colloid and Interface Science, Vol. 26, No. 1, 1968, pp. 62-69. doi:10.1016/0021-9797(68)90272-5

[13] G. Buchel, M. Grun, K. K. Unger, A. Matsumoto and T Taszuo, "Tailored Synthesis of Nanostructured Silica: Control of Particle Morphology, Particle Size and Pore Size," Supramolecular Science, Vol. 5, No. 3-4, 1998, pp. 253-259. doi:10.1016/S0968-5677(98)00016-9

[14] S. Han, W. Hou, W. Dang, J. Xua, J. Hu and D. Li, "Synthesis of Rod-like Mesoporous Silica Using Mixed Surfactants of Cetyltrimethylammonium Bromide and Cetyltrimethylammonium Chloride as Templates," Materials Letters, Vol. 57, No. 29, 2003, pp. 4520-4524. doi:10.1016/S0167-577X(03)00355-0

[15] E. R. Essien, O. A. Olaniyi, L. A. Adams and R. O. Shaibu, "Highly Porous Silica Network Prepared from Sodium Metasilicate," Journal of Metals, Materials and Minerals, Vol. 21, No. 2, 2011, pp. 7-12.

[16] T. Witoon, M. Chareonpanich and J. Limtrakul, "Synthesis of Bimodal Porous Silica From Rice Husk Ash via Sol-Gel Process Using Chitosan as Template," Materials Letters, Vol. 62, No. 10-11, 2008, pp. 1476-1479. doi:10.1016/j.matlet.2007.09.004

[17] N. Pijarn, A. Jaroenworaluck, W. Sunsaneeyametha and R. Stevens, "Synthesis and Characterization of NanosizedSilica Gels Formed under Controlled Conditions," Powder Technology, Vol. 203, No. 3, 2010, pp. 462-468. doi:10.1016/j.powtec.2010.06.007

[18] T. Li, T and T. Wang, "Preparation of Silica Aerogel from Rice Hull ash by Drying at Atmospheric Pressure," Materials Chemistry and Physics, Vol. 112, No 2, 2008, pp. 398-401. doi:10.1016/j.matchemphys.2008.05.066

[19] R. R. Zaky, M. M. Hessien, A. A. El-Midany, M. H. Khedr, E. A. Abdel-Aal and K. A. El-Barawy, "Preparation of Silica Nanoparticles from Semi-burned Rice Straw Ash," Powder Technology, Vol. 185, No. 1, 2008, pp. 3135. doi:10.1016/j.powtec.2007.09.012

[20] O. A. Olasupo and J. A. Omotoyinbo, "Moulding Properties of a Nigerian Silica-Clay Mixture for Foundry Use," Applied Clay Science, Vol. 45, No. 4, 2009, pp. 244-247. doi:10.1016/j.clay.2009.05.001

[21] P. M. Shewale, A. V. Rao, A. P. Rao and S. D. Bhagat, 
"Synthesis of Transparent Silica Aerogels with Low Density and Better Hydrophobicity by Controlled Sol-Gel Route and Subsequent Atmospheric Pressure Drying," Journal of Sol-Gel Science and Technology, Vol. 49, No. 3, 2009, pp. 285-292. doi:10.1007/s10971-008-1888-8

[22] F. Bauer, H. J. Gläsel, U. Decker, H. Ernst, A. Freyer, E. Hartmann, V. Sauerland and R. Mehnert, "Trialkoxysilane Grafting onto Nanoparticles for the Preparation of Clear Coat Polyacrylate Systems with Excellent Scratch Performance," Progress in Organic Coatings, Vol. 47, No. 2, 2003, pp. 147-153. doi:10.1016/S0300-9440(03)00117-6

[23] I. A. Rahman, P. Venjayakumaran, C. S. Sipaut, J. Ismail and C. K. Chee, "Effect of Drying Techniques on the Morphology of Silica Nanoparticles Synthesized Via Sol-Gel Process," Ceramics International, Vol. 34, No. 8, 2008, pp. 2059-2066. doi:10.1016/j.ceramint.2007.08.014

[24] H. Wang, W. Zhong, Q. Du, Y. Yang, V. Okamoto and S. Inoue, "Novel Polyimide/Silica Nanohybrids from Water Glass," Polymer Bulletin, Vol. 51, No. 1, 2003, pp. 63-68. doi:10.1007/s00289-003-0188-2

[25] U. K. Bangi, A. V. Rao and A. P. Rao, "A New Route for Preparation of Sodium-Silicate-Based Hydrophobic Silica Aerogels via Ambient-Pressure Drying," Science and Technology of Advanced Materials, Vol. 9, No. 3, 2008, pp. 1-10. doi:10.1088/1468-6996/9/3/035006

[26] S. W. Hwang, T. Y. Kim and S. H. Hyun, "Effect of Surface Modification Conditions on the Synthesis of Mesoporous Crack-Free Silica Aerogel Monoliths from Waterglass via Ambient-drying," Microporous and Mesoporous Materials, Vol. 130, No. 1, 2010, pp. 295-302. doi:10.1016/j.micromeso.2009.11.024

[27] D. M. Schmidt, G. W. Scherer and J. M. Anderson, "Shrinkage During Drying of Silica Gel," Journal of NonCrystalline Solids, Vol. 188, No. 3, 1995, pp. 191-206. doi:10.1016/0022-3093(95)00187-5

[28] L. A. Adams, R. O. Shaibu, E. R. Essien and A. Oki, "Bentonite Clay and Waterglass Porous Monoliths via the Sol-Gel Process," Journal of Metals, Materials and Minerals, Vol. 21, No. 2, 2011, pp. 1-6.

[29] C. J. Lee, G. S. Kim and S. H. Hyun, "Synthesis of Silica Aerogels from Water Glass via New Modified Ambient Drying," Journal of Materials Science, Vol. 37, No. 11, 2002, pp. 2237-2241. doi:10.1023/A:1015309014546

[30] P. Suresh, G. Kanchawa and P. Sundaramoorthi, "Growth and Characterization Studies of MnHP Single Crystal in
Silica Gel Medium," Journal of Minerals \& Materials Characterization \& Engineering, Vol. 8, No. 5, 2009, pp. 439-453.

[31] H. S. Mansur, R. L. Orefice and A. A. P. Mansur, "Characterization of Poly(vinyl alcohol)/Poly(ethylene glycol) Hydrogels and PVA-Derived Hybrids by Small-Angle Scattering and FTIR Spectroscopy," Polymer, Vol. 45, No. 21, 2004, pp. 7193-7202. doi:10.1016/j.polymer.2004.08.036

[32] R. Almeida and G. Pantano, "Structural Investigation of Silica Gel Films by Infrared Spectroscopy," Journal of Applied Physics, Vol. 68, No. 8, 1990, pp. 1225-1232. doi:10.1063/1.346213

[33] V. Lenza and W. L. Vasconcelos, "Preparation of Silica by Sol-gel Method Using Formamide," Materials Research, Vol. 4, No. 3, 2001, pp. 189-194. doi:10.1590/S1516-14392001000300008

[34] C. Bhavornthanayod and P. Rungrojchaiporn, "Synthesis of Zeolite a Membrane from Rice Husk Ash," Journal Metals, Materials and Minerals, Vol. 19, No. 2, 2009, pp. 79-83.

[35] P. Sooksaen, S. Suttiruengwong, K. Oniem, K. Ngamlamiad and J. Atireklapwarodom, "Fabrication of Porous Bioactive Glass-Ceramics via Decomposition of Natural Fibres," Journal of Metals, Materials and Minerals, Vol. 18, No. 2, 2008, pp. 85-91.

[36] U. Kalapathy, A. Proctor and J. Shultz, "A Simple Method for Production of Pure Silica from Rice Hull Ash," Bioresource Technology, Vol. 73, No. 3, 2000, pp. 99-106. doi:10.1016/S0960-8524(99)00112-1

[37] B. Rager and V. Krysztafkiewicz, "Effect of Electrolytes and Surfactants on Physicochemical Properties and Porous Structures of Hydrated Silicas," Colloids and Surfaces A: Physicochemical and Engineering Aspects, Vol. 125, No. 2-3, 1997, pp. 121-130. doi:10.1016/S0927-7757(97)00063-0

[38] S. A. K. Jeeliani, G. Benoist, K. S. Joshi, R. Gunde, D. Kellenberger and E. J. Windhab "Creaming and Aggregation of Particles in Suspensions," Colloids and Surfaces A: Physicochemical and Engineering Aspects, Vol. 263, No. $1-3,2005$, pp. 379-389. doi:10.1016/j.colsurfa.2005.01.003

[39] D. G. Bika, M. Gentzler and V. Michaels, "Mechanical Properties of Agglomerates," Powder Technology, Vol. 117, No. 1-2, 2001, pp. 98-112. doi:10.1016/S0032-5910(01)00318-7 